University of Nebraska - Lincoln

DigitalCommons@University of Nebraska - Lincoln

June 1983

RECIPROCAL RECURRENT SELECTION FOR 21-DAY LITTER

WEIGHT OF CROSSBRED GILTS. II. REPRODUCTIVE

PERFORMANCE OF PUREBRED FEMALES PRODUCING

PUREBRED AND TWO-WAY CROSS LITTERS AND PERFORMANCE OF PUREBRED AND CROSSBRED PIGS

L. D. Young

Oklahoma State University-Stillwater

I. T. Omtvedt

Oklahoma State University-Stillwater, iomtvedt1@unl.edu

J. A. Whatley Jr.

US Department of Agriculture, Clay Center, NE

R. K. Johnson

University of Nebraska-Lincoln, rjohnson5@unl.edu

Follow this and additional works at: https://digitalcommons.unl.edu/animalscifacpub

Part of the Animal Sciences Commons

Young, L. D.; Omtvedt, I. T.; Whatley, J. A. Jr.; and Johnson, R. K., "RECIPROCAL RECURRENT SELECTION FOR 21-DAY LITTER WEIGHT OF CROSSBRED GILTS. II. REPRODUCTIVE PERFORMANCE OF PUREBRED FEMALES PRODUCING PUREBRED AND TWO-WAY CROSS LITTERS AND PERFORMANCE OF PUREBRED AND CROSSBRED PIGS" (1983). Faculty Papers and Publications in Animal Science. 29.

https://digitalcommons.unl.edu/animalscifacpub/29

This Article is brought to you for free and open access by the Animal Science Department at DigitalCommons@University of Nebraska - Lincoln. It has been accepted for inclusion in Faculty Papers and Publications in Animal Science by an authorized administrator of DigitalCommons@University of Nebraska - Lincoln. 


\title{
RECIPROCAL RECURRENT SELECTION FOR 21-DAY LITTER WEIGHT OF CROSSBRED GILTS. II. REPRODUCTIVE PERFORMANCE OF PUREBRED FEMALES PRODUCING PUREBRED AND TWO-WAY CROSS LITTERS AND PERFORMANCE OF PUREBRED AND CROSSBRED PIGS ${ }^{1}$
}

\author{
L. D. Young ${ }^{2}$, I. T. Omtvedt ${ }^{3}$, J. A. Whatley, Jr. ${ }^{4}$ and R. K. Johnson ${ }^{5}$ \\ US Department of Agriculture, Clay Center, NE 68933 \\ and \\ Oklahoma State University-Stillwater $\mathbf{7 4 0 7 4}$
}

\section{Summary}

This paper reports estimates of correlated genetic change in reproductive performance of purebred gilts producing two-way cross litters and purebred sows producing purebred litters as well as postweaning performance of two-way cross and purebred pigs produced during reciprocal recurrent selection (RRS) between Line 8 (Duroc) and Line 9 (Beltsville No. 1) for 21-d litter weight production of crossbred gilts. A randomly mated control line developed from a crossbred foundation was maintained to monitor environmental change. Data were adjusted for age of dam, inbreeding of dam, inbreeding of litter (or pig) and linear and quadratic effects of day born within season. The traits evaluated were: litter size, litter weight and average pig weight/litter at birth and weaning (42 d); postweaning average daily gain; age at $90.7 \mathrm{~kg}$ and backfat thickness at $90.7 \mathrm{~kg}$. Two data sets were analyzed; the first set included seven seasons of data with purebred gilts producing two-way cross litters, and the second set included seven seasons of data with purebred sows producing purebred litters. No

\footnotetext{
'Journal Article 4278, Oklahoma Agr. Exp. Sta., Stillwater.

${ }^{2}$ Roman L. Hruska U.S. Meat Animal Research Center, ARS, USDA, Clay Center, NE.

${ }^{3}$ Present address: Agr. Exp. Sta., Univ. of Nebraska, Lincoln 68583.

${ }^{4}$ Agr. Exp. Sta., Oklahoma State Univ., Stillwater 74074.

${ }^{5}$ Present address: Dept. of Anim. Sci., Univ. of Nebraska, Lincoln 68583.

Received December 16, 1982.

Accepted May 3, 1983.
}

estimates of environmental trend were significant in either set of data. In the first data set, only the estimate of genetic change in backfat thickness of two-way cross pigs was significant and it was in the desired direction. All other estimates were small and did not approach significance. In the second data set, estimates of genetic trend were greater in Line 9 than in Line 8. Estimates of genetic trend in Line 9 were significant for average pig weight at birth, age at $90.7 \mathrm{~kg}$ and backfat probe at $90.7 \mathrm{~kg}$, and approached significance for litter size at weaning and average daily gain. The estimates were undesirable for preweaning traits and desirable for postweaning traits. The estimates of genetic trend in Line 8 were of the same sign as those in Line 9, but only the estimate for backfat thickness was significant. The decrease in size of purebred litters in Line 9, and to some degree line 8 , suggests an accelerated accumulation of homozygosity beyond that accounted for by adjustment for pedigree inbreeding. The fact that Line 9 showed a greater decrease than Line 8 suggests that most of the increase in level of reproduction of crossbred gilts may have resulted from genetic change in Line 9 rather than Line 8 , or that favorable alleles were being fixed in Line 8 and unfavorable alleles in Line 9.

(Key Words: Reciprocal Recurrent Selection, Swine, Litter Weight, Correlated Response.)

Introduction

The theory of reciprocal recurrent selection (RRS) suggests that selection for more heterozygous test-cross progeny would accelerate the increase in homozygosity of parental lines 
YOUNG ET AL.

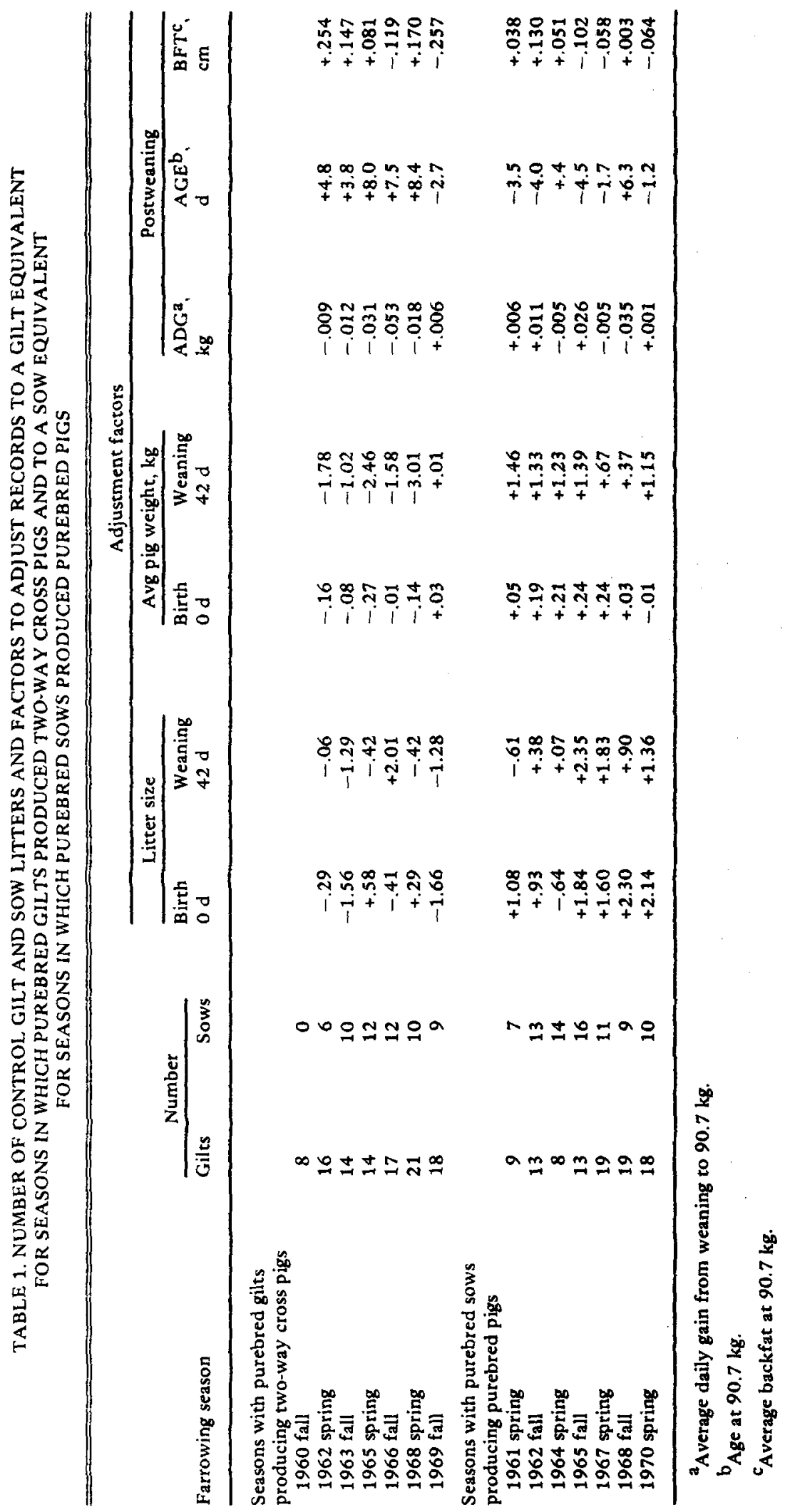


above that accounted for by pedigree inbreeding, with a consequent decline in purebred performance relative to the trend in crossbred performance (Comstock, 1961). Thus, in order to evaluate fully the utility of RRS, it is essential to evaluate the correlated genetic response occurring in the supporting populations.

The general design of an experiment to evaluate the effectiveness of RRS for 21-d litter weight of crossbred half-sib gilts has been presented along with selection applied, realized heritability and genetic trends for productivity of crossbred gilts (Young et al., 1983). Selection was practiced among purebreds and response was measured as productivity of two-way cross gilts. Estimates of genetic change were favorable but, generally, were not significant for measures of productivity of crossbred gilts.

The purpose of this paper is to present estimates of correlated genetic change in reproductive performance of purebred gilts producing two-way cross litters and of purebred sows producing purebred litters and genetic change in postweaning performance of two way cross and purebred pigs produced during RRS for 21-d litter weight of crossbred gilts.

\section{Experimental Procedure}

Experimental Design. Six cycles of RRS between Line 8 (Duroc) and Line 9 (Beltsville No. 1) were completed from 1960 through 1970 at the Fort Reno Livestock Research Station, E1 Reno, Oklahoma. The foundation stock and experimental procedures were described in detail by Young et al. (1983).

Each cycle of selection required three seasons. A random mated control line was farrowed each season. Each season, except the fall of 1960 , approximately $40 \%$ of the farrowings in the control line were from second-parity sows chosen at random from those farrowing the previous season. Two data sets were established and analyzed separately; the first data set included seven generations of performance from the first season of each cycle (purebred gilts producing two-way cross litters), and the second data set included seven generations of performance from the second season of each cycle (purebred sows producing purebred litters).

Probe backfat thickness was determined from an average of six lean meter readings taken at approximately $90.7 \mathrm{~kg}$ live weight on

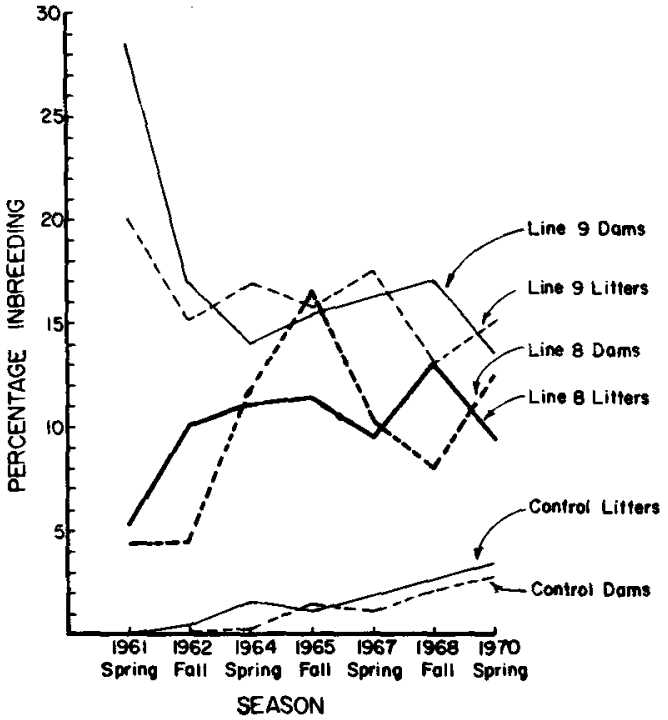

Figure 1. Inbreeding of dam and litter by line for seasons with purebred sows producing purebred litters.

both sides of the animal $3.8 \mathrm{~cm}$ from the midline over the first rib, last rib and last lumbar vertebrae. Probes were adjusted to a constant weight of $90.7 \mathrm{~kg}$ according to procedures described by Durham and Zeller (1955).

Age of Dam Adjustments. Gilts and secondparity sows produced litters within the control line in each season, except the 1960 fall farrowing season when all litters were produced by gilts. In the first season of each cycle, purebred Line 8 and Line 9 gilts produced two-way cross pigs. Therefore, data from control line sows farrowing in these seasons were adjusted to a gilt equivalent basis. In the second season of each cycle, purebred Line 8 and Line 9 sows produced purebred pigs. Therefore, data from control line gilts farrowing in these seasons were adjusted to a sow equivalent basis. Based upon previous analyses of control line data (Young et al., 1983), the parity adjustments were made by using the observed mean difference between sow and gilt records within each season (table 1). The components of litter weight (litter size and average pig weight) were adjusted and multiplied together to calculate an age of dam adjusted litter weight.

Inbreeding Adjustments. In both data sets, control line data were subject to the effects of inbreeding of dam and litter. Data on crossbred litters and pigs were subject only to 
inbreeding of dam effects, while data on purebred litters were subject to inbreeding of dam and litter effects. There were wide fluctuations from season to season in level of inbreeding of dam when Line 8 and Line 9 gilts were producing two-way cross pigs, and in inbreeding of dam and litter when Line 8 and Line 9 sows were producing purebred pigs. For illustration, the mean level of inbreeding of dam and litter are shown in figure 1 for each season and line for the data from seasons in which purebred sows produced purebred litters. Data from seasons in which purebred gilts produced two-way cross litters would show the same pattern for inbreeding of Line 8 and Line 9 dams because the same females are represented in both sets of data; crossbred pigs would have zero inbreeding and control line trends would be very similar to those for the control line in figure 1 .

The differences between lines in the accumulation of inbreeding are confounded with genetic change. Therefore, all data were adjusted for inbreeding of dam and litter (or pig) when appropriate. Because the intent of the adjustment was to remove the effects of changes in level of inbreeding from performance trends and not to compare breed means, data in each line were adjusted to the mean level of inbreeding of dam and litter (or pig) for that line. The mean level of inbreeding of dam was $1.2,9.7$ and $16.9 \%$ for control, Line 8 and Line 9, respectively. Corresponding mean levels of inbreeding of litter (or pig) were $1.5,10.0$ and $16.0 \%$. Data from Line 8 and Line 9 females were adjusted for inbreeding of litter in the data set when they farrowed as sows and produced purebred pigs, but not when they farrowed as gilts and produced crossbred pigs.

Litter size, average pig weight/litter and litter weight were adjusted for inbreeding effects as described by Young et al. (1983). Effects of inbreeding of dam and pig on postweaning traits were estimated from seven seasons of data of contemporary performance of straightbred Line 8, Line 9 and control line sows. Data were analyzed by least-squares procedures as described by Harvey $(1964,1975)$. The full model used to initiate analysis of postweaning traits for inbreeding effects included effects of farrowing season, line, line $x$ season, linear regression on inbreeding of dam, linear regression on inbreeding of pig and the interaction of the regressions with line. The interaction of the linear effects of inbreeding of dam and inbreeding of litter with line were not significant and were deleted from the model.

The effect of a $10 \%$ increase in inbreeding of pig, as estimated from the reduced model, was $-.010 \pm .004 \mathrm{~kg}, 2.07 \pm .72 \mathrm{~d}$ and $.0025 \pm$ $.0203 \mathrm{~cm}$ for average daily gain, age at $90.7 \mathrm{~kg}$ and backfat at $90.7 \mathrm{~kg}$, respectively; the corresponding effects for a $10 \%$ increase in inbreeding of dam were $-.006 \pm .004 \mathrm{~kg}, .39 \pm .80 \mathrm{~d}$ and $.0152 \pm .0229 \mathrm{~cm}$. These values were in agreement with literature estimates (Dickerson et al., 1954; Bradford et al., 1958; Bereskin et al., 1968; Krehbeil et al., 1971b; Leymaster and Swiger, 1981), and were used to adjust all postweaning data for inbreeding of dam and pig where appropriate.

Statistical Analysis. After making appropriate

TABLE 2. AVERAGE NUMBER OF OBSERVATIONS PER SEASON BY LINE OF

DAM FOR ALL TRAITS EVALUATED FOR SEASONS WITH PUREBRED GILTS PRODUCING TWO-WAY CROSS PIGS (DATA SET 1) AND SEASONS WITH PUREBRED SOWS PRODUCING PUREBRED PIGS (DATA SET 2)

\begin{tabular}{lllll}
\hline Data set & Dam line & Reproduction & & Growthb \\
\hline 1 & Control & 24 & $84 / 33 / 53$ & $80 / 33$ \\
& Line 9 & 23 & $76 / 6 / 70$ & $73 / 6$ \\
& Line 8 & 24 & $74 / 5 / 79$ & $69 / 5$ \\
2 & Control & 26 & $100 / 32 / 69$ & $91 / 31$ \\
& Line 9 & 23 & $78 / 32 / 42$ & $73 / 31$ \\
& Line 8 & 22 & $85 / 35 / 51$ & $68 / 35$ \\
\hline
\end{tabular}

\footnotetext{
${ }^{a}$ Number of litters.

b Number of gilts, boars and barrows, respectively, with data on average daily gain and age at $90.7 \mathrm{~kg}$.

Number of gilts and boars, respectively, with backfat thickness data.
} 
adjustments for age of dam, inbreeding of dam and inbreeding of litter, data were analyzed by least-squares procedures to estimate seasonline means. Two data sets were analyzed. The first set included the seven seasons when purebred gilts produced two-way cross litters, and the second set included the seven seasons when purebred sows produced purebred litters. The model for each data set included the effects of line, season, season $x$ line and the linear and quadratic effects of day born within season (subclass regression). The effects of sex, sex $x$ season and sex $x$ line were added to the model to analyze postweaning traits. All litters that had at least one live pig at birth are included in the analyses of all preweaning traits, except average pig weaning weight/litter where only litters with at least one live pig at weaning were included. Because of small numbers and missing subclasses, barrows were not included in the backfat thickness data. Boars, barrows and gilts were included in the data on postweaning daily gain and age at $90.7 \mathrm{~kg}$. The average number of observations per season are presented in table 2 by line of dam for each data set. Leastsquares dam line means and residual mean squares are presented in table 3 for both data sets in order to characterize these populations.

Genetic change in the control line was assumed to be zero. Therefore, the environmental trend in each set of data was estimated by regressing control line means on cycle of selection.

Genetic trend in each set of data was calculated by regressing the deviation of Line 8 and Line 9 means from the control line means on cycle of selection.

Standard errors of the estimates of environmental and genetic change were adjusted for drift variance as described by Young et al. (1983).

\section{Results and Discussion}

\section{Purebred Gilts Producing}

Two-Way Cross Pigs

Environmental Trend. The estimates of environmental trend for litter size, litter weight and average pig weight at birth and weaning were positive but nonsignificant (table 4). Most of the change in litter birth weight $(.57 \mathrm{~kg} /$ cycle) was due to the change in litter size (.46 $\mathrm{pig} / \mathrm{cycle}$ ) rather than average pig weight/litter $(.00 \mathrm{~kg} / \mathrm{cycle})$. However, change in litter weaning weight $(6.16 \mathrm{~kg} / \mathrm{cycle})$ was attributable to changes in both litter size $(.31 \mathrm{pig} / \mathrm{cycle})$ and average pig weight/litter $(.44 \mathrm{~kg} / \mathrm{cycle})$. These differ somewhat from the environmental trends estimated in the seven seasons of data reported by Young et al. (1983). They reported small and nonsignificant changes in traits measured at birth, and somewhat smailer but nonsignificant positive changes in traits measured at weaning. The reason for the discrepancy between estimates from the two data sets probably results from the low level of reproduction in the control line in the first season in this data set. This probably reflects a true environmental effect, because reproduction of Line 8 and Line 9 dams was also low for that season.

The estimates of environmental trend for postweaning traits were not significant, but there was a tendency for all traits to improve. Average daily gain increased slightly $(.004$ $\mathrm{kg} /$ cycle), age at $90.7 \mathrm{~kg}$ decreased $(-2.01$ $\mathrm{d} /$ cycle) and backfat thickness decreased $(-.063 \mathrm{~cm} /$ cycle $)$.

Genetic Change. Estimates of genetic change are presented in table 5 for reproductive performance of Line 8 and Line 9 gilts producing reciprocal cross litters and for the postweaning performance of the crossbred pigs.

Only the estimates of genetic change for backfat thickness were significant. The mean genetic changes in backfat thickness were $-.098 \pm .049$ and $-.135 \pm .050 \mathrm{~cm} / \mathrm{cycle}$ for crossbred pigs out of Line 8 and Line 9 gilts, respectively.

All other estimates of genetic change were small and did not approach significance. Estimates of genetic change of preweaning traits were negative, except for average pig weight at birth for Line 8 and 9 gilts $(.02 \pm .02 \mathrm{~kg} / \mathrm{cycle})$ and for litter birth weight for Line 9 gilts $(.01 \pm$ $.36 \mathrm{~kg} /$ cycle). Young et al. (1983) reported positive changes in these traits measured on $8 \times$ 9 and $9 \times 8$ gilts. The selection criterion in this experiment was litter 21-d weight produced by the crossbred gilts. Preweaning traits are largely under control of the dam. If RRS selection is successful, the differences in genetic change noted above would be expected, because gains in combining ability, contributed by the effects of specific combining ability on gene frequencies at overdominant loci, would eventually lead to an accelerated increase in homozygosity in the pure strains and a decrease in level of performance (Comstock, 1961). While the genetic changes were small and negative in this data set, 
YOUNG ET AL.

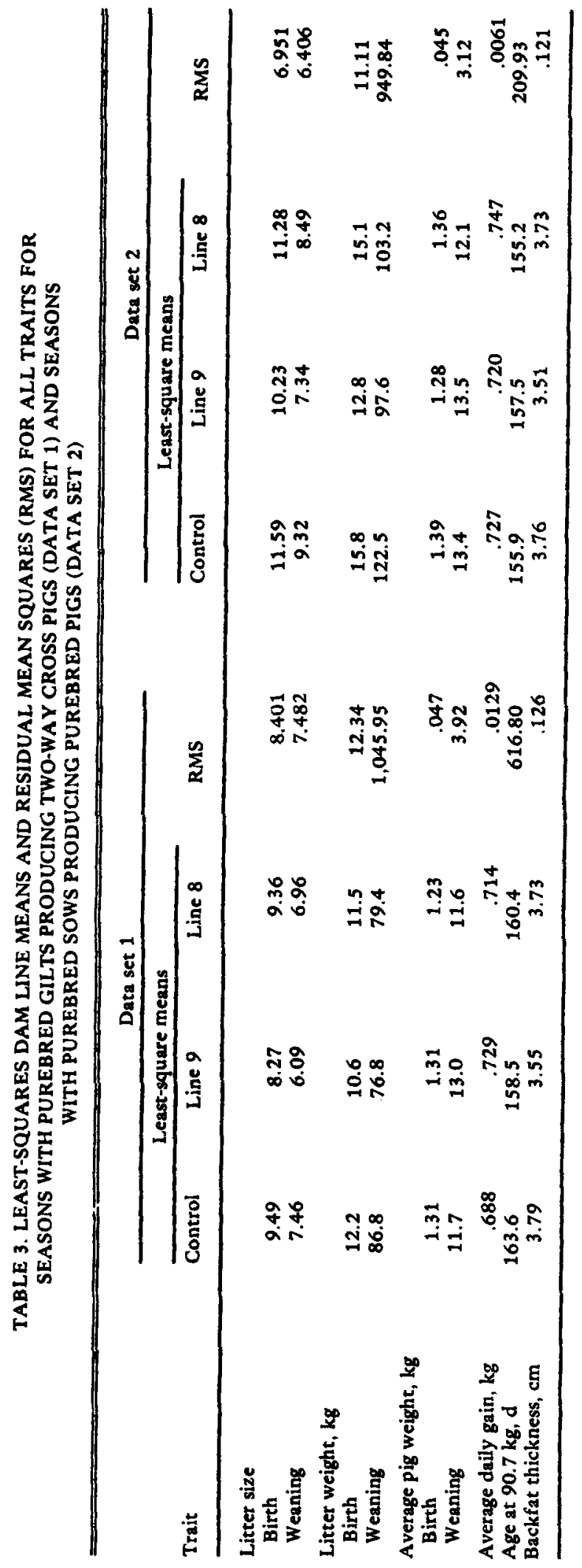


TABLE 4. ESTIMATES OF ENVIRONMENTAL TREND IN CONTROL GILTS CONTEMPORARY TO PUREBRED GILTS PRODUCING TWO-WAY CROSS PIGS AND IN CONTROL SOWS CONTEMPORARY TO PUREBRED SOWS PRODUCING PUREBRED PIGS

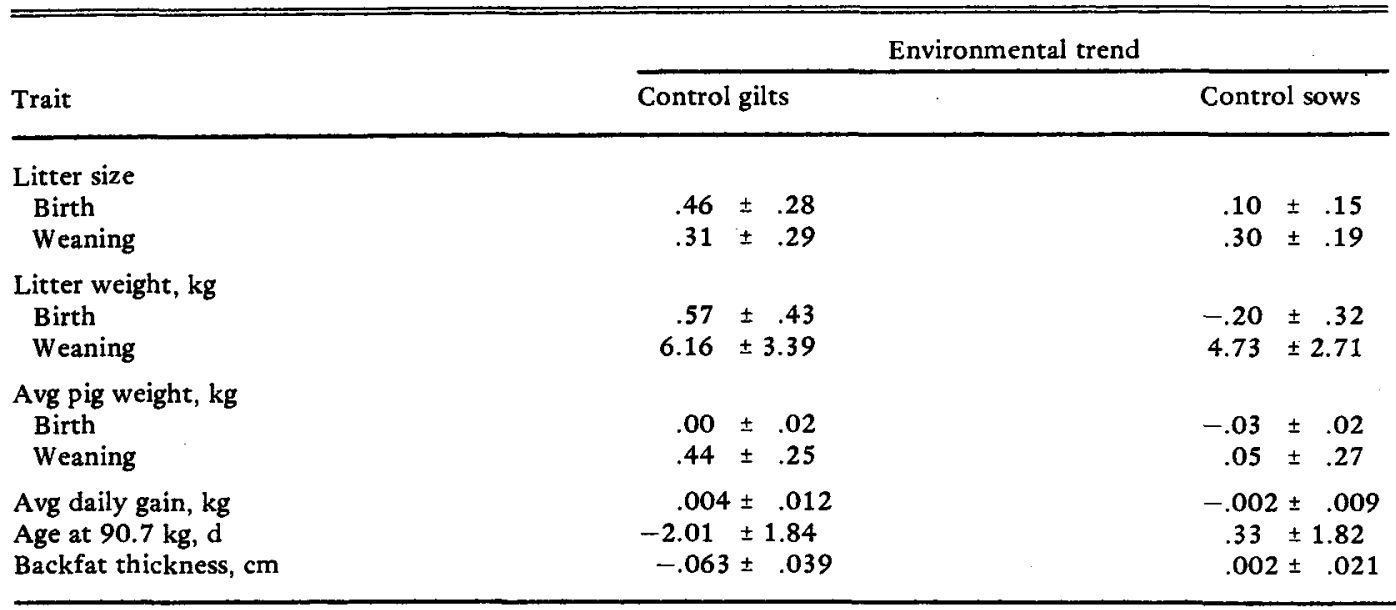

some of the detrimental effects of the increased homozygosity of purebred females may have been mediated by reciprocal crossing. In a comprehensive analysis of several crossbreeding studies, Johnson (1980) reported crossbred litters averaged .10 and .70 more pigs/litter at birth and weaning, respectively, than purebred litters; crossbred pigs also averaged .04 and .64 $\mathrm{kg}$ heavier at birth and weaning.

There was no genetic change in average daily gain of crossbred pigs out of Line 8 gilts $(.000 \pm$
$.013 \mathrm{~kg} /$ cycle), but a positive, though nonsignificant, increase in average daily gain of crossbred pigs out of Line 9 gilts $(.007 \pm .013$ $\mathrm{kg} / \mathrm{cycle})$. There was essentially no genetic change in age at $90.7 \mathrm{~kg}$ for pigs out of Line 8 $(.35 \pm 2.61 \mathrm{~d} / \mathrm{cycle})$ or Line 9 gilts $(-.02 \pm 2.58$ d/cycle).

The results of this analysis indicate that RRS for 21-d litter weight of crossbred gilts resulted in very little genetic change in reproduction of purebred females producing crossbred

TABLE 5. REGRESSION OF DEVIATION OF LINE MEANS FROM CONTROL LINE ON CYCLE OF SELECTION FOR PUREBRED GILTS PRODUCING TWO-WAY CROSS PIGS AND FOR PUREBRED SOWS PRODUCING PUREBRED PIGS

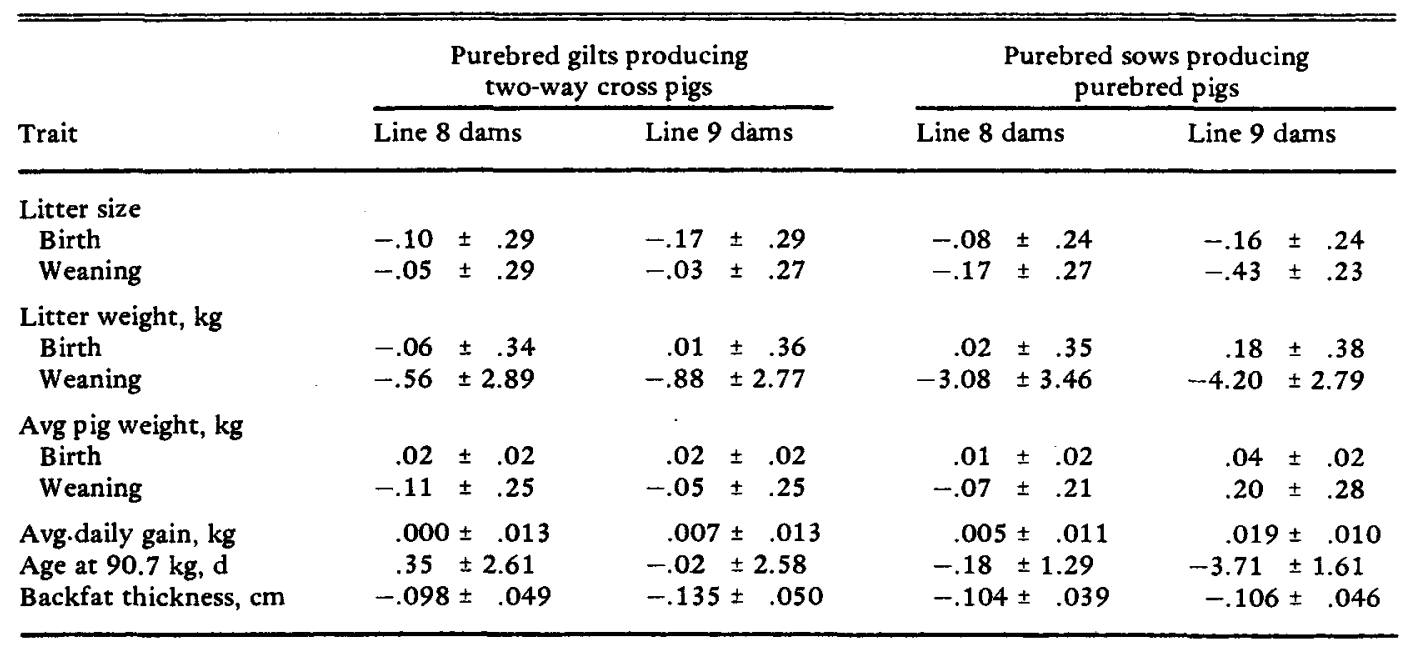


litters or in the postweaning growth of the single-cross pigs. There was a significant desirable change in backfat thickness of the single-cross pigs.

\section{Purebred Sows Producing Purebred Pigs}

Environmental Trend. No estimates of environmental trend were significantly different from zero (table 4). The environmental trend for litter size at birth was small but positive $(.10 \pm .15 \mathrm{pigs} / \mathrm{cycle})$. The trend for litter birth weight was small and negative $(-.20 \pm .32$ pigs/cycle), due to a negative trend in pig birth weight $(-.03 \pm .02 \mathrm{~kg} /$ cycle $)$. The trends for litter size, litter weight and average pig weight at weaning were all positive. The enviornmental trend for average daily gain, age at $90.7 \mathrm{~kg}$ and backfat probe were in the undesirable direction, but very small. These results are consistent with previous analyses of control line data that showed no significant changes in level of performance over the duration of the experiment (Edwards et al., 1971; Young et al., 1983).

Genetic Change. Estimates of genetic change are presented in table 5 . Line 8 and Line 9 had small, nonsignificant, negative genetic trends for litter size at birth. The genetic change for litter size at weaning was larger in the negative direction than the change for litter size at birth in both lines and the change approached significance for litter size at weaning in Line 9.

Line 9 had a significant positive genetic change for average pig birth weight, while the corresponding value for Line 8 was nonsignificant, but also positive. The genetic trend for average pig weaning weight was nonsignificant for both lines, but it was positive for Line 9 $(.20 \pm .28 \mathrm{~kg} / \mathrm{cycle})$ and negative for Line 8 $(-.07 \pm .21 \mathrm{~kg} /$ cycle $)$.

Estimates of genetic change in litter birth weight were small and positive in both lines. Both lines had similar negative genetic trends for litter weight at weaning, but they were nonsignificant.

Estimates of genetic change in postweaning average daily gain $(.019 \pm .010 \mathrm{~kg} / \mathrm{cycle})$, age at $90.7 \mathrm{~kg}(-3.71 \pm 1.61 \mathrm{~d} /$ cycle $)$ and backfat thickness $(-.106 \pm .046 \mathrm{~cm} /$ cycle) were in the desirable direction for Line 9. In Line 8, the estimate of genetic change was significant and desirable for backfat thickness $(-.104 \pm .039$ $\mathrm{cm} /$ cycle), but not significant or large for average daily gain $(.005 \pm .011 \mathrm{~kg} / \mathrm{cycle})$ or age at $90.7 \mathrm{~kg}(-.18 \pm 1.79 \mathrm{~d} /$ cycle $)$. These estimates may not reflect true correlated response to selection because they reflect some degree of selection between males within a litter. One male was selected from each of the top five litters; therefore, selection could be practiced within litter. Selected males averaged .03 and $.01 \mathrm{~kg} / \mathrm{d}$ higher average daily gain and 1.2 and $.8 \mathrm{~mm}$ less backfat than unselected littermates in Line 8 and Line 9, respectively.

As mentioned previously, Comstock (1961) pointed out that under RRS, gains in combining ability contributed by the effects of specific combining ability on gene frequencies at overdominant loci would eventually lead to an accelerated increase in homozygosity in the pure strain and a decrease in level of performance. Even after adjusting for estimated effects of increased pedigree inbreeding, the data on reproduction of Line 8 and Line 9 females in purebred matings tend to support this statement. However, the adjustment for inbreeding effects could be biased and, thereby, contribute to this apparent effect. Level of reproduction decreased at a greater rate in purebred Line 9 matings than in purebred Line 8 matings, suggesting that rate of accelerated accumulation of homozygosity might be greater in Line 9 than in Line 8 , or that more favorable alleles were fixed in Line 8 and more unfavorable alleles were fixed in Line 9. Krehbeil et al. (1971a,b), Hetzer et al. (1977) and Bereskin and Hetzer (1981) also reported negative genetic trends in performance of purebred populations under RRS schemes.

Young et al. (1983) reported positive, but generally nonsignificant, genetic trends in reproductive traits of crossbred gilts produced by reciprocal crossing of Line 8 and Line 9. Thus, the mean level of reproductive performance of the crossbred gilts was higher at the end of the study than at the beginning. Results of this study indicate that reproductive performance of purebred females, when mated within line, was lower at the end of the study than at the beginning. If heterosis is defined as the superiority of the crossbred over the average of the parental breeds, this experiment suggests that this RRS scheme was only moderately successful in improving the mean level of reproductive performance of the crossbred gilt, but was effective in increasing the level of heterosis. The latter achievement is not very important if it was brought about largely, 
or even partly, by reducing purebred performance.

\section{Literature Cited}

Bereskin, B. and H. O. Hetzer. 1981. Reciprocal recurrent selection in swine: Postweaning growth. J. Anim. Sci. 53:1446.

Bereskin, B., C. E. Shelby, K. E. Rowe, W. E. Urban, Jr., C. T. Blunn, A. B. Chapman, V. A. Garwood, L. N. Hazel, J. F. Lasely, W. T. Magee, J. W. McCarty and J. A. Whatley, Jr. 1968. Inbreeding and swine productivity traits. J. Anim. Sci. 27:339.

Bradford, G. E., A. B. Chapman and R. H. Grummer. 1958. Effects of inbreeding, selection, line crossing and top crossing in swine. I. Inbreeding and selection. J. Anim. Sci. 17:426.

Comstock, R. E. 1961. Reciprocal recurrent selection (RRS) with reference to swine breeding. 24th Annu. Rep. Regional Swine Breeding Laboratory, Ames, IA.

Dickerson, G. E., C. T. Blunn, A. B. Chapman, R. M. Kottman, J, L. Kinder, E. J. Warwick, J. A. Whatley, Jr., M. L. Baker, J. L. Lush and L. M. Winters. 1954. Evaluation of selection in developing inbred lines of swine. Missouri Agr. Exp. Sta. Res. Bull. 551.

Durham, R. M. and J. H. Zeller. 1955. Using the probing technique in selecting breeding swine on farms. J. Anim. Sci. 14:1180 (Abstr.).

Edwards, R. L., I. T. Omtvedt and J. A. Whatley. 1971. Genetic analysis of a swine control popula- tion. I. Population stability. J. Anim. Sci. 32:179. Harvey, W. R. 1964. Computing procedures for a generalized least-squares analysis program. Analysis of variance Conf., Colorado State Univ., Fort Collins (Mimeo.).

Harvey, W. R. 1975. Least-squares analysis of data with unequal subclass numbers. USDA, ARS H-4.

Hetzer, H. O., R. H. Miller and R. C. Kling. 1977. Effectiveness of reciprocal recurrent selection for improving preweaning performance in swine. $J$. Anim. Sci. 45:989.

Johnson, R. K. 1980. Heterosis and breed effects on swine. North Central Regional Pub. No. 262.

Krehbeil, E. V., H. O. Hetzer, A. E. Flower, G. E. Dickerson, W. R. Harvey and L. A. Swiger. 1971a. Effectiveness of reciprocal selection for performance of crosses between Montana No. 1 and Yorkshire swine. I. Preweaning traits. J. Anim. Sci. 32:191.

Krehbeil, E. V., H. O. Hetzer, A. E. Flower, G. E. Dickerson, W. R. Harvey and L. A. Swiger. 1971b. Effectiveness of reciprocal selection for performance of crosses between Montana No. 1 and Yorkshire swine. II. Postweaning traits. J. Anim. Sci. 32:211.

Leymaster, K. A. and L. A. Swiger. 1981. Selection for increased leanness of Yorkshire swine. III. Inbreeding effects on secondary traits. J. Anim. Sci. 53:620.

Young, L. D., I. T. Omtvedt, J. A. Whatley, Jr. and R. K. Johnson. 1983. Reciprocal recurrent selection for 21-day litter weight of crossbred gilts. I. Selection applied and genetic change in reproduction of crossbred gilts. J. A nim. Sci. 57:1418. 